Atmos. Chem. Phys., 13, 10171-10183, 2013

www.atmos-chem-phys.net/13/10171/2013/

doi:10.5194/acp-13-10171-2013

(c) Author(s) 2013. CC Attribution 3.0 License.

\title{
Aerosol physical and chemical properties retrieved from ground-based remote sensing measurements during heavy haze days in Beijing winter
}

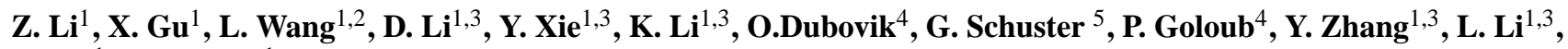 \\ Y. $\mathrm{Ma}^{1}$, and $\mathrm{H} . \mathrm{Xu}^{1}$ \\ ${ }^{1}$ State Environmental Protection Key Laboratory of Satellites Remote Sensing, Institute of Remote Sensing and Digital Earth \\ of Chinese Academy of Sciences, Beijing 100101, China \\ ${ }^{2}$ International Institute for Earth System Science, Nanjing University, Nanjing 210093, China \\ ${ }^{3}$ University of Chinese Academy of Sciences, Beijing 100049, China \\ ${ }^{4}$ Laboratoire d'Optique Atmosphérique, Université Lille 1, Villeneuve d'Ascq 59655, France \\ ${ }^{5}$ NASA Langley Research Center, Hampton, VA 23681, USA \\ Correspondence to: L. Wang (w18394722@126.com)
}

Received: 29 January 2013 - Published in Atmos. Chem. Phys. Discuss.: 21 February 2013

Revised: 5 September 2013 - Accepted: 6 September 2013 - Published: 16 October 2013

\begin{abstract}
With the increase in economic development over the past thirty years, many large cities in eastern and southwestern China are experiencing increased haze events and atmospheric pollution, causing significant impacts on the regional environment and even climate. However, knowledge on the aerosol physical and chemical properties in heavy haze conditions is still insufficient. In this study, two winter heavy haze events in Beijing that occurred in 2011 and 2012 were selected and investigated by using the ground-based remote sensing measurements. We used a CIMEL CE318 sunsky radiometer to retrieve haze aerosol optical, physical and chemical properties, including aerosol optical depth (AOD), size distribution, complex refractive indices and aerosol fractions identified as black carbon (BC), brown carbon $(\mathrm{BrC})$, mineral dust (DU), ammonium sulfate-like (AS) components and aerosol water content (AW). The retrieval results from a total of five haze days showed that the aerosol loading and properties during the two winter haze events were comparable. Therefore, average heavy haze property parameters were drawn to present a research case for future studies. The average AOD is about 3.0 at $440 \mathrm{~nm}$, and the Ångström exponent is 1.3 from 440 to $870 \mathrm{~nm}$. The fine-mode AOD is 2.8 corresponding to a fine-mode fraction of 0.93 . The coarse particles occupied a considerable volume fraction of the bimodal size distribution in winter haze events, with the mean parti-
\end{abstract}

cle radius of 0.21 and $2.9 \mu \mathrm{m}$ for the fine and coarse modes respectively. The real part of the refractive indices exhibited a relatively flat spectral behavior with an average value of 1.48 from 440 to $1020 \mathrm{~nm}$. The imaginary part showed spectral variation, with the value at $440 \mathrm{~nm}$ (about 0.013 ) higher than the other three wavelengths (about 0.008 at $675 \mathrm{~nm}$ ). The aerosol composition retrieval results showed that volume fractions of BC, BrC, DU, AS and AW are 1, 2, 49, 15 and $33 \%$, respectively, on average for the investigated haze events. The preliminary uncertainty estimation and comparison of these remote sensing results with in situ $\mathrm{BC}$ and $\mathrm{PM}_{2.5}$ measurements are also presented in the paper.

\section{Introduction}

Haze can reduce severely atmospheric visibility due to increased extinction of suspended solid or liquid particles. One major constituent of haze is aerosol particles, such as dust and soot from fuel- or coal burning. Haze formation is thought to be closely related to meteorological conditions and air pollution (Sun et al., 2006; Lai and Sequeira, 2001). When haze occurs, environmental air is usually polluted, and thus affects human health. In addition, it has significant effects on cloud formation and regional climate 
(Okada et al., 2001; Menon et al., 2002). In recent years, the haze pollution has drawn growing worldwide concerns, especially in developing countries. The rapid increase in energy consumption and the amount of vehicles in the past three decades as well as the high population density have caused serious particulate mater (PM) pollution in Beijing (He et al., 2002). Haze event has been observed frequently in Beijing (Sun et al., 2006), during the cold winter and spring seasons because of the enhanced heating, traffic and industrial emissions, and especially the stable weather conditions. Meanwhile, dust blown from local and the northern arid regions is still a perpetual phenomenon in Beijing during the dry winter and spring seasons. The mineral dust component further mixing with local aerosols makes the nature of haze aerosols in Beijing distinct from others. However, studies on the haze pollution in Beijing are rather limited, and simultaneous observation of physical and optical properties as well as the chemical characteristics of haze aerosol even less so.

In this paper, two haze events occurring in the winters of February 2011 and 2012 over Beijing were studied. We measured attenuation of direct solar beam and sky radiation distribution by using a new-generation CIMEL polarized sunsky radiometer equipped with dual wheels (an additional polarizer wheel) differing from standard CIMEL radiometers that are equipped only with one filter wheel (Li et al., 2009), to derive accurate aerosol optical depth (AOD) and comprehensive aerosol properties such as particle size distribution, single-scattering albedo (SSA) and refractive indices (Holben et al., 1998; Dubovik et al., 2000, 2006). These aerosol optical and microphysical parameters can provide a base for retrieval of the aerosol chemical composition information, which allows for estimation of the aerosol component fraction without affecting the ambient status of atmospheric particles.

\section{Measurement and methodology}

\subsection{Observation site and instrument}

In this study, the observation site $\left(116.37^{\circ} \mathrm{E}, 40.00^{\circ} \mathrm{N}\right)$ in Beijing is located on the building roof ( $\sim 59$ ma.s.l.) of the Institute of Remote Sensing and Digital Earth, Chinese Academy of Sciences. The instrument we used is a CIMEL CE318-DP sun-sky radiometer, \#350 in the AErosol RObotic NETwork (AERONET) (Holben et al., 1998). It has eight wavelengths, nominally centered at $340,380,440,500$, $675,870,1020$ and $1640 \mathrm{~nm}$ with bandwidth from 2 to $10 \mathrm{~nm}$ for the purpose of aerosol observation. Measurements are automatically scheduled with direct sun irradiance measurements each of about $15 \mathrm{~min}$ and angular sky radiance scanning of about $1 \mathrm{~h}$ each. In practice, the direct sun attenuation measurements are performed three times within about $1 \mathrm{~min}$, and its variability in the period is used to detect clouds (Smirnov et al., 2000). Sky scanning in almucantar and solar principal plane (SPP) geometry for intensity and polarization measurements can be used to retrieve aerosol optical, physical and chemical properties. The sky measurements are performed wavelength by wavelength, taking about 5-8 min depending on instrument scenario and wavelengths appointed by the user. Calibration of the direct sun measurements of the radiometer (\#350) was done twice by comparison with the AERONET master instrument (\#245) on 2 November 2009, and the high-mountain Langley calibration performed at the Litang site ( $3913 \mathrm{~m}$ and AOD less than about 0.03 at $870 \mathrm{~nm}$ ) on 13 October 2011. The AOD uncertainty is then estimated to be about $0.01-0.02$. The sky radiance was calibrated following the method of $\mathrm{Li}$ et al. (2008) with uncertainties estimated to be $3-5 \%$. The polarization calibration was performed in the laboratory on 28 October 2009 with uncertainties estimated to be about 0.01 ( $\mathrm{Li}$ et al., 2010).

\subsection{Two haze events in Beijing winter}

Many studies propose to use the visibility as a proxy to identify the haze event (e.g. Bäumer et al, 2008). Here, we consider a three-parameter criterion to select haze from our measurements, which includes relative humidity $(\mathrm{RH})<90 \%$ (Deng et al., 2008), AOD $(440 \mathrm{~nm})>1.0$ and the Ångström exponent $\alpha>1.0$. Firstly, there is a relationship between AOD and visibility, and an $\operatorname{AOD}(440 \mathrm{~nm})$ greater than 1.0 corresponds to approximately a visibility lower than about $5 \mathrm{~km}$ in the standard atmospheric model, which can be recognized as moderate or heavy haze. Secondly, the threshold on $\alpha$ is set to distinguish haze from the dust storm cases, which can also have high AOD values, but usually with a much lower $\alpha$. Thirdly, the ambient humidity criterion is useful to distinguish fog from haze conditions $(\mathrm{Wu}$ et al., 2005). According to these criteria, we selected two typical haze events: one during the period of 22-23 February 2011, and the other during that of 27-29 February 2012. Figure 1 shows the measured AOD and Ångström exponent (440-870 nm) during the two haze events. In the first event (2011), the average AOD $(440 \mathrm{~nm})$ is higher than that of the second event (2012). In 2012 event, the Ångström exponent is higher than 2011, indicating either more fine-mode particles relative to the coarse-mode particles or smaller radius fine-mode particles. It should be noted that AOD at $440 \mathrm{~nm}$ may be associated with much larger uncertainties than the other three wavelengths due to reaching the measurement limitation of the CE318 instrument (Sinyuk et al., 2012) in these extremely heavy haze events. According to Zhao et al. (2012), the maximum $\operatorname{AOD}(440 \mathrm{~nm})$ uncertainty can be up to $4 \%$ when simulated using Junge size distribution, and depending on solar zenith angle and aerosol properties. We can assume the similar uncertainty level in our case when the raw digital signal is less than 10 at $440 \mathrm{~nm}$, which counts for less than 30 percentage points for all days in the studied period except for 23 January 2011 (about 80 percentage points). 


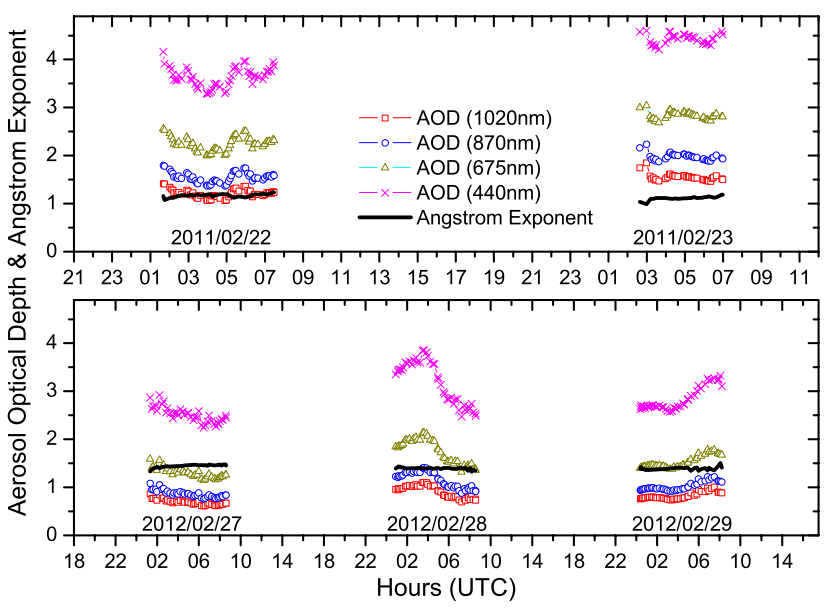

Fig. 1. Time variation of $A O D$ and the Angström exponent (440-870 nm) during two haze events in Beijing.

\subsection{Retrieval of aerosol physical properties}

We utilize the comprehensive aerosol retrieval code developed by Dubovik et al. $(2000,2006)$ in this study, which is also the standard inversion algorithm for AERONET aerosol products. The retrieved aerosol property parameters include the particle size distribution (typical uncertainty of $25 \%$ ) and the wavelength-dependent refractive indices (typical uncertainty of 0.04 for real parts and $40 \%$ for imaginary parts) as well as other aerosol optical parameters like SSA (typical uncertainty of 0.03) (Dubovik et al., 2000; Li et al., 2009). The algorithm employs the spheroid model (Volten et al., 2001) to improve the performance when dealing with coarse particles, while the discrete ordinates method (Nakajima and Tanaka, 1988; Stamnes et al., 1988) is used to solve the radiative transfer equation. In the retrieval, the ground reflectance is assumed to be Lambertian with albedo obtained from a $5 \mathrm{yr}$, half-monthly average MODIS climatology (Li et al., 2006). We carry out cloud screening by using the triplet direct-sun measurement stability (Smirnov et al., 2000) and almucantar measurement asymmetry (Holben et al., 2006). In Fig. 2, we show an example to illustrate the fit of sky radiance $(L)$ measurements based on the retrieved aerosol parameters. The residual $\varepsilon$ is defined as

$\varepsilon_{L}(\lambda ; \Theta)=\frac{L^{\mathrm{cal}}(\lambda ; \Theta)-L^{\text {meas }}(\lambda ; \Theta)}{L^{\text {meas }}(\lambda ; \Theta)}$,

where $\lambda$ is the wavelength, $\Theta$ is the scattering angle and the superscripts ${ }^{\text {meas }}$ and ${ }^{\text {cal }}$ denote the measured and calculated (using the retrieved aerosol parameters) sky radiance, respectively. The radiance used in this study is normalized by $\pi / E_{0}$, with $E_{0}$ the extraterrestrial solar irradiance. The smaller sky radiance residual (comparable with the radiance calibration uncertainty of 3-5\%) suggests that the inversion algorithm performs well in the case of heavy haze events. Moreover, taking the advantage of the CE318-DP instrument, we can also verify the retrieval results by validating residuals on the independent degree of linear polarization (DOLP) measurements as follows:

$\varepsilon_{P}(\lambda ; \Theta)=P^{\mathrm{cal}}(\lambda ; \Theta)-P^{\text {meas }}(\lambda ; \Theta)$,

where $P^{\text {meas }}$ is the DOLP measured by CE318-DP and $P^{\text {cal }}$ is the calculated DOLP using the retrieved aerosol property parameters. From Fig. 2, we find the residuals on $P$ are less than 0.01 at all wavelengths (average of all measurement angles), which agrees well with the calibration accuracy of the polarization measurements.

\subsection{Retrieval of aerosol chemical composition}

In general, aerosol is a complicated mixture of liquid water and dry components. According to the aerosol scattering and absorbing properties, the dry aerosol particles can be divided into two categories: the first is the absorbing components like black carbon (BC), dust (DU) and the still poorly understood brown carbon $(\mathrm{BrC})$ generated by combustion processes (Moosmuller et al., 2009); and the second is the scattering (non-absorbing) components such as sulfate, nitrate and sea salt etc. Here, we assume a mixture model of aerosols including five components, i.e., BC, BrC, DU, ammonium sulfate (AS) and water (AW), as shown in Fig. 3 and Table 1, considering that sea salt can be generally neglected in Beijing and the ammonium sulfate can be used as a proxy of non-absorbing dry components (Schuster et al., 2005; Dey et al., 2006; Arola et al., 2011). This model is an extension of the three-component model of Schuster et al. (2005) and four-component model of Arola et al. (2011). To apply this model to remote sensing measurement, we consider using information obtained from the spectral variation of the imaginary part of the refractive index as well as the spectral variation of SSA.

The average aerosol refractive indices over Beijing in 2010 are presented in the left-hand panel of Fig. 4. The enhanced absorption (larger imaginary part) at $440 \mathrm{~nm}$ reveals the presence of spectrally dependent absorbing aerosols like DU or $\mathrm{BrC}$, while $\mathrm{BC}$ usually causes wavelength-independent absorption (Bond and Bergstrom, 2006). In order to include dust and $\mathrm{BrC}$ in the retrieval simultaneously, we consider using the size-dependent absorption parameter, i.e., the SSA (Dubovik et al., 2002), as DU and BrC usually have different particle size. In general, DU components are usually coarse particles, while $\mathrm{BrC}$ generated by combustion processes is typically fine particles. It should also be noted that not all coarse-mode particles in Beijing are dust particles as some are fly ash emitted during coal combustion. On the right-hand panel of Fig. 4, we exhibit the average spectral SSA obtained from January to December 2010 over Beijing for periods with predominately coarse (Ångström exponent $\mathrm{AE}<0.6$ ) and fine particles (AE > 1.5)(Dubovik et al., 2002; Schuster et al., 2006; Eck et al., 2010). The SSA spectral trends from 675 and $870 \mathrm{~nm}$ show a clear difference (an increased pattern 

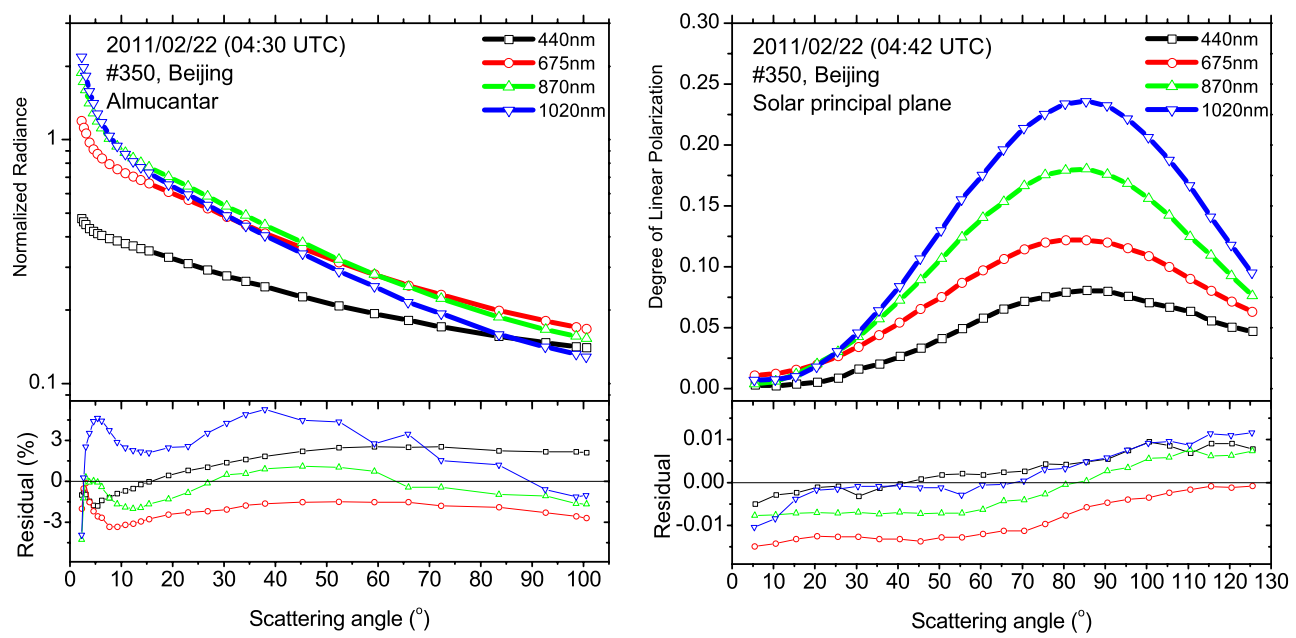

Fig. 2. Fit of the normalized sky radiance and degree of linear polarization by using the retrieved aerosol parameters for haze example on 22 February 2011 in Beijing.

Table 1. Aerosol component groups and their parameters used in the retrieval of chemical fractions from remote sensing measurements. $n$ is the real part of the refractive index, $k_{\text {blue }}$ is the imaginary refractive index at blue band, $k_{\text {red }}$ is the imaginary refractive index at red band, MAE is the mass absorption efficiency and $\rho$ is density.

\begin{tabular}{llccccccc}
\hline No. & $\begin{array}{l}\text { Representative } \\
\text { components }\end{array}$ & $n$ & $k_{\text {blue }}$ & $k_{\text {red }}$ & $\begin{array}{c}\text { MAE } \\
(675 \mathrm{~nm})\end{array}$ & $\begin{array}{c}\text { MAE } \\
(870 \mathrm{~nm})\end{array}$ & $\begin{array}{c}\rho \\
\left(\mathrm{g} \mathrm{cm}^{-3}\right)\end{array}$ & $\begin{array}{c}\text { Group } \\
\text { Abbr. }\end{array}$ \\
\hline 1 & Black carbon & 1.95 & 0.66 & 0.66 & 8.14 & 6.32 & 2.0 & $\mathrm{BC}$ \\
2 & Brown carbon & 1.53 & 0.063 & 0.005 & 0.067 & 0.05 & 1.8 & $\mathrm{BrC}$ \\
3 & Mineral dust & 1.57 & 0.01 & 0.004 & 0.045 & 0.035 & 2.6 & $\mathrm{DU}$ \\
4 & Ammonium sulfate & 1.53 & $1 \times 10^{-7}$ & $1 \times 10^{-7}$ & 0 & 0 & 2.3 & $\mathrm{AS}$ \\
5 & Aerosol water content & 1.33 & 0 & 0 & 0 & 0 & 1.0 & $\mathrm{AW}$ \\
\hline
\end{tabular}

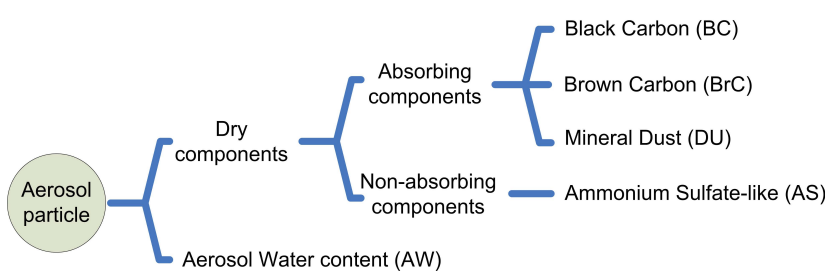

Fig. 3. Aerosol component model used in the chemical composition retrieval.

for coarse particles, but a decreased pattern for fine particles) for the two cases. We employ this behavior in our retrieval to help distinguish DU from BrC.

The detailed algorithm on the aerosol chemical composition retrieval has been presented in a recent paper (Wang et al., 2013). Here we provide the description of algorithm when applied to sun-sky radiometer data:

i. Input. The program reads into aerosol optical and physical properties retrieved from CE318 and converts them into parameters used in the component fraction retrieval, including $n$ from the average of real part of aerosol refractive index at four bands $(440,675,870$, $1020 \mathrm{~nm}), k_{\text {blue }}$ from the imaginary part of aerosol refractive index at $440 \mathrm{~nm}, k_{\text {red }}$ from the imaginary parts from 675 to $1020 \mathrm{~nm}$ and dSSA obtained by $(\operatorname{SSA}(870 \mathrm{~nm})-\operatorname{SSA}(675 \mathrm{~nm}))$. Moreover, size distribution and AOD at 675 and $870 \mathrm{~nm}$ are also read into and useful in step four.

ii. Initialization. Refractive indices of five components (BC, BrC, DU, AS, AW), mass absorption efficiency (MAE) and density of each component are set according to related literatures. Detailed numbers used in this study are listed in Table 1.

iii. Discretization of the solution space. We set steps of volume fractions of components to $0.2,1,5$ and $5 \%$ for $\mathrm{BC}, \mathrm{BrC}, \mathrm{DU}$ and $\mathrm{AW}$, respectively, and the remaining fractions to AS. We use "TN" to denote the total number of combination of possible solutions (each solution includes five volume fractions of aerosol components), i.e., $\left(f_{i}, i=1,5\right)_{j}$ with $j=1$, TN.

iv. Calculation of parameters of aerosol component mixture. We assume the internal mixture of all components 

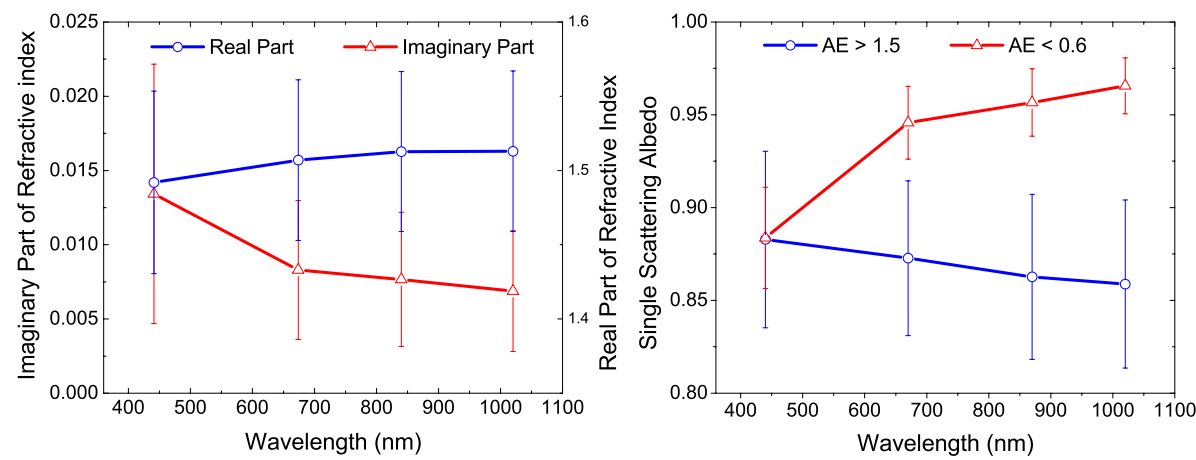

Fig. 4. Average aerosol refractive indices (left) and single-scattering albedo (right) obtained from sun-sky radiometer measurements from January 2010 to December 2010 in Beijing. The error bar shows the standard deviation, and AE on the right-hand panel denotes the Ångström exponent. $\mathrm{AE}<0.6$ denotes coarse-mode-dominated cases, while $\mathrm{AE}>1.5$ denotes fine-mode-dominated cases.

and employ the volume average mixing rule (Heller, $1995)$ to calculate $n^{\mathrm{cal}}, k_{\text {blue }}^{\mathrm{cal}}$ and $k_{\text {red }}^{\mathrm{cal}}$ for each volume fraction solution $\left(f_{i}\right)_{j}$. Moreover, we assume spherical particles and utilize the size distribution, AOD, MAE and aerosol density to calculate dSSA ${ }^{\text {cal }}$ following method described in Wang et al. (2013).

v. Calculation of residuals for each piece of input information. The optimization of function $\Psi\left(\varepsilon_{n}, \varepsilon_{k(\text { blue })}, \varepsilon_{k(\text { red })}\right.$, $\left.\varepsilon_{\mathrm{dSSA}}\right)$ provides the best solution for the volume fraction retrieval, where residuals on each input information defined as

$$
\begin{aligned}
& \varepsilon_{n}=\frac{\left|n^{\text {cal }}-n\right|}{n}, \\
& \varepsilon_{k(\text { blue })}=\frac{\left|k_{\text {blue }}^{\text {cal }}-k_{\text {blue }}\right|}{k_{\text {blue }}}, \\
& \varepsilon_{k(\text { red })}=\frac{\left|k_{\text {red }}^{\text {cal }}-k_{\text {red }}\right|}{k_{\text {red }}}, \\
& \varepsilon_{\text {dSSA }}=\frac{\left|\mathrm{dSSA}^{\text {cal }}-\mathrm{dSSA}\right|}{\mid \text { dSSA } \mid} .
\end{aligned}
$$

vi. Finding the best solution by the optimization method. In the processing of optimization of function $\psi$, in order to avoid problems with weighting four kinds of input information ( $n, k_{\text {blue }}, k_{\text {red }}$ and dSSA), we utilize a "rank position" (RP) priority strategy instead of using the traditional method of absolute residual minimization. Firstly, we number an integer series $\mathrm{RP}_{j}\left(\varepsilon_{n}\right)$ related to each member of solution space $\left(\mathrm{f}_{i}\right)_{j}$ with $i=1,5$ and $j=1$, TN. The value of $\operatorname{RP}_{j}\left(\varepsilon_{n}\right)$, or the rank position, is calculated based on $\varepsilon_{n}$, while $\mathrm{RP}_{j}\left(\varepsilon_{n}\right)=1$ for the minimum $\varepsilon_{n}$ and $\mathrm{RP}_{j}\left(\varepsilon_{n}\right)=\mathrm{TN}$ for the maximum $\varepsilon_{n}$. Secondly, we create similarly the integer series $\mathrm{RP}_{j}\left(\varepsilon_{k}\right.$ (blue) $), \mathrm{RP}_{j}\left(\varepsilon_{k \text { (red })}\right)$ and $\mathrm{RP}_{j}\left(\varepsilon_{\mathrm{dSSA}}\right)$. Thirdly, the $j$ corresponds to $\min \left(\mathrm{RP}_{j}\left(\varepsilon_{n}\right)+\mathrm{RP}_{j}\left(\varepsilon_{k(\text { blue })}\right)+\mathrm{RP}_{j}\left(\varepsilon_{k(\text { red })}\right)+\mathrm{RP}_{j}\left(\varepsilon_{\mathrm{dSSA}}\right)\right)$, which provides the optimization of function $\psi$, and the corresponding $\left(f_{1}, f_{2}, f_{3}, f_{4}, f_{5}\right)_{j}$ is the best solution for all kinds of information on $n, k_{\text {blue }}, k_{\text {red }}$ and dSSA. vii. Output. The program prints fractions of $\mathrm{BC}, \mathrm{BrC}, \mathrm{DU}$, AS and AW components corresponding to the best solution.

\subsection{Error estimation of aerosol component fraction retrieval}

Uncertainties in the retrieved aerosol component fractions come mainly from two sources. One is the retrieval method itself, including assumptions on the component mixing state, on the particle shape, on the refractive indices of representative components and so on, which is difficult to assess and might be not the dominative uncertainty source at present. Another uncertainty source is the errors in the input information, i.e., errors of the optical and physical properties from remote sensing measurements, which will be preliminarily evaluated here.

Uncertainties of the optical and physical properties obtained from sun-sky radiometer retrievals have been carefully assessed (Dubovik et al., 2000). Typical uncertainty in the real part of the refractive index is about 0.04 , while in the imaginary part it is about $40 \%$, and in SSA about 0.03 . Following the algorithm description in Sect. 2.4, the input parameter $n$ is assumed spectrally constant and obtained from the average of real parts of refractive indices at four bands of sun-sky radiometer. The expected uncertainty of $n$ is then estimated to be $\left(N_{\lambda}\right)^{-1 / 2} \times 0.04=0.02$, where $N_{\lambda}$ equals 4 . Similarly, expected uncertainty in $k_{\text {blue }}$ is $40 \%$, while in $k_{\text {red }}$ it is about $23 \%$ thanks to the average of three bands. The expected uncertainty in dSSA is difficult to estimate, and we can temporally set it to the uncertainty of SSA, i.e., 0.03. It should be mentioned that the band difference form of dSSA (i.e., $\mathrm{dSSA}=\operatorname{SSA}(870 \mathrm{~nm})-\mathrm{SSA}(675 \mathrm{~nm}))$ should be able to eliminate most of systematical errors in SSA, and thus uncertainty in dSSA could be less than 0.03 .

We employ here the yearly average aerosol optical and physical properties of Beijing for the year 2010 as the aerosol model in the error assessment. The refractive indices and SSA are shown in Fig. 4, and the retrieved component 

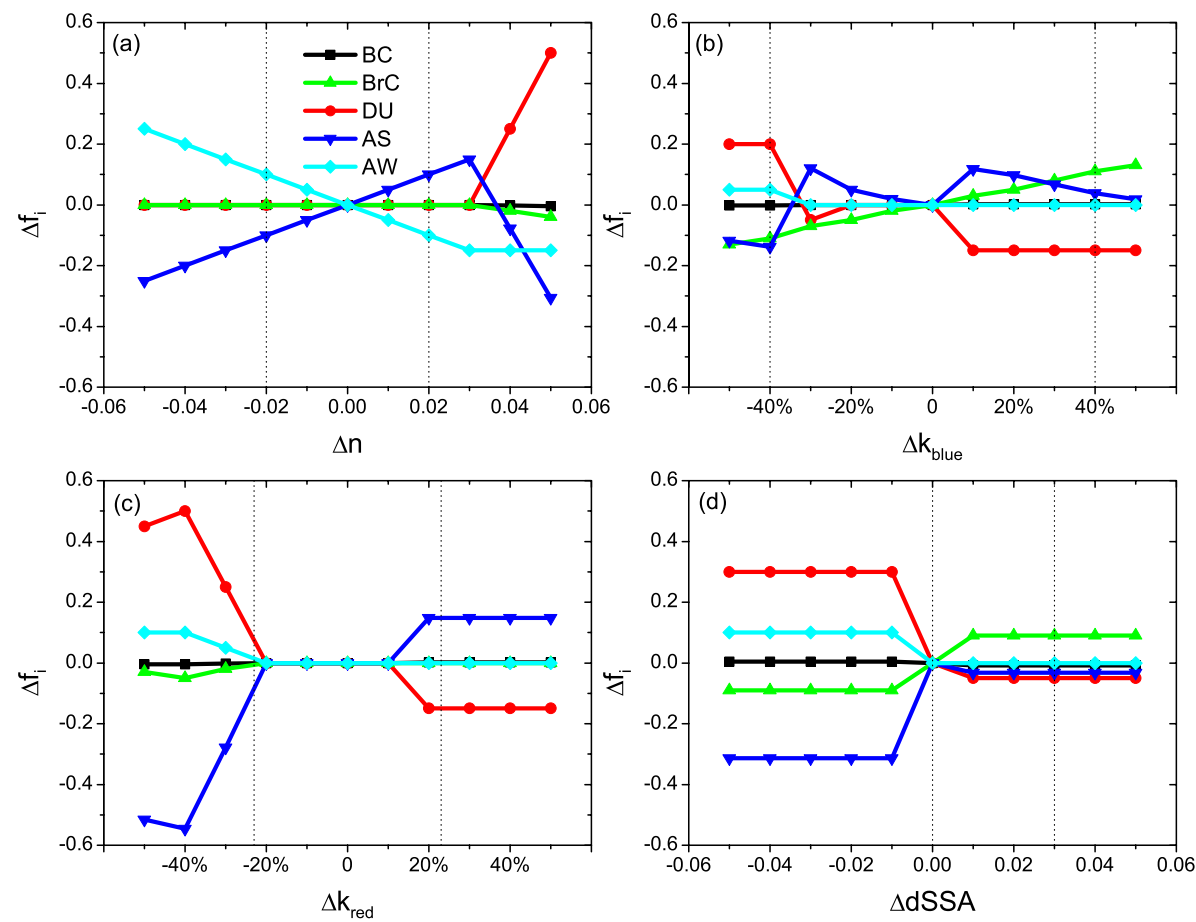

Fig. 5. Uncertainty in the retrieval of aerosol component fractions. Errors in $n, k_{\text {blue }}, k_{\text {red }}$ and dSSA are assessed with their expected uncertainty ranges marked by dot lines in each graph.

fractions are $0.8,14,15,55.2$ and $15 \%$ for $\mathrm{BC}, \mathrm{BrC}, \mathrm{DU}$, AS and AW, respectively. To test sensitivity of component fraction retrieval to errors of input information, we set the variation range and steps for $n([-0.05,0.05], 0.01), k_{\text {blue }}$ $([-50 \%, 50 \%], 10 \%), k_{\text {red }}([-50 \%, 50 \%], 10 \%)$ and dSSA ([-0.05, 0.05], 0.01). The uncertainty estimation results are presented in Fig. 5.

It can be seen from Fig. 5a that absorbing components (BC, $\mathrm{BrC}$ and DU) are basically not sensitive to uncertainty in $n$, while non-absorbing components (AS and $\mathrm{AW}$ ) show counteracting behaviors, and their maximum uncertainties are $10 \%$, corresponding to the expected uncertainty range of $n$. In Fig. 5b, we find that strong absorbing BC is nearly insensitive to $\Delta k_{\text {blue }}$, while weak absorbing components $(\mathrm{BrC}$ and DU) are sensitive. The AS curve shows roughly opposite variation versus that of DU, and the uncertainty of AW

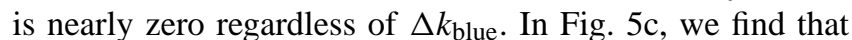
none of the component fractions are affected by uncertainty of $\Delta k_{\text {red }}$ in the range from -20 to $10 \%$. Moreover, AS and DU are the most affected components, and their corresponding curves are symmetric. In Fig. 5d, when $\triangle$ dSSA is less than -0.01 , component fraction uncertainties are larger, especially for DU and AS. This is explained by the characteristics of the retrieval algorithm, which employs dSSA to distinguish DU from $\mathrm{BrC}$, as introduced in Sect. 2.4. Once the sign of dSSA has changed due to $\triangle \mathrm{dSSA}$, the DU and $\mathrm{BrC}$ fractions, as well as those of AS and AW, will change significantly. However, sign changes of dSSA are expected to be rare in the retrieval; for example, the uncertainty assessment of SSA in Dubovik et al. (2000) showed that spectral SSA curves are usually shifted entirely when suffering from measurement uncertainties that will keep the sign of dSSA and not change. Therefore, in Fig. 5d, we consider only $\triangle$ dSSA from 0 to 0.03 , which results in smaller uncertainties in component fractions.

Figure 5 provides a case study to assess the aerosol component fraction uncertainties. Considering that it is unlikely that all error sources $\left(\Delta \mathrm{n}, \Delta k_{\text {blue }}, \Delta k_{\text {red }}, \Delta\right.$ dSSA) coincidently reach the maximum, we assume that the possible uncertainty of each component corresponds to the maximum error caused by one of four error sources. Therefore, the maximum uncertainties in $\mathrm{BC}, \mathrm{BrC}, \mathrm{DU}, \mathrm{AS}$ and $\mathrm{AW}$ are roughly estimated to be $0.008,0.11,0.2,0.15$ and 0.1 associated to error sources of $\Delta \mathrm{dSSA}, \Delta k_{\text {blue }}, \Delta k_{\text {blue }}, \Delta k_{\text {red }}$ and $\Delta \mathrm{n}$, respectively. Comparing with the model's component fraction used in the assessment, the relative uncertainties in this case are about $100,80,140,30$ and $70 \%$ for BC, BrC, DU, AS and AW components, respectively. We should mention that aerosol component uncertainties, such as those in BC from emission inventories, can be $200 \%$ or more (Schuster et al., 2005), and thus our retrievals are valuable and uncertainties can be expected to further decrease in the future. Moreover, it should be mentioned that in a stable atmosphere; for example, in the case of heavy haze, which can be verified by the stable AOD or other optical and physical properties, the sun-sky radiometer can provide retrieval results 5-8 times in 

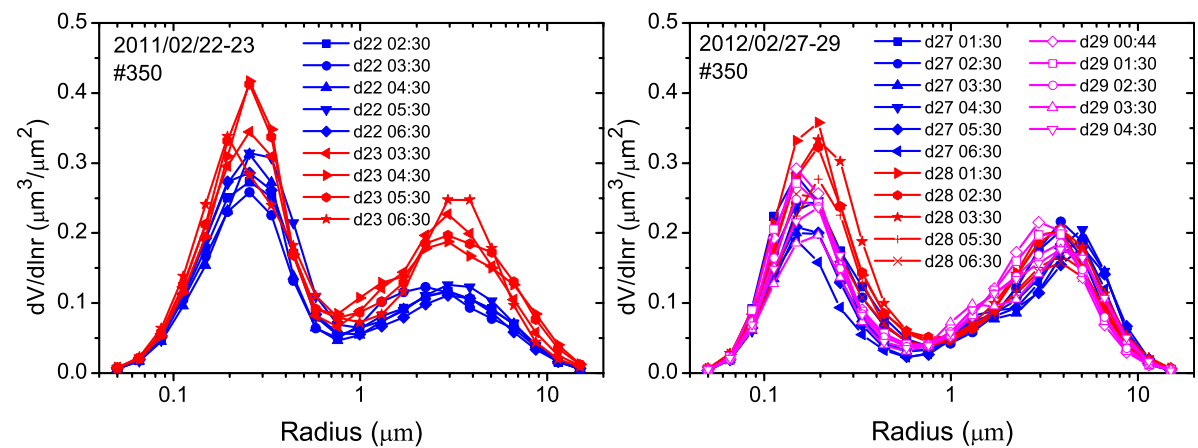

Fig. 6. Aerosol size distribution (dV/dln $r$ ) retrieved on haze day (left, 2011 event; right, 2012 event).

a day, and taking an average can significantly diminish uncertainties. Therefore, in this study we will present mainly daily average component fractions.

\section{Results}

\subsection{Aerosol physical characteristics during haze events}

\subsubsection{Size distribution}

Particles' size distribution is a key aerosol physical parameter for showing clearly the fine- and coarse-particle fractions in the atmosphere. Figure 6 shows the aerosol size distribution retrieved from sun-sky radiometer measurements during the two haze events. In the 2011 event, the size distribution value on 23 February is higher than that of 22 February, which corresponds to higher AOD on 23 February, as shown in Fig. 1. Meanwhile, the both obviously higher fine and coarse modes on 23 February cause an increase in AOD, while the Ångström exponent remains stable compared to 22 February. In the 2012 event, it contains more coarse particles compared with 2011 cases. In the 2011 haze event, it contains 39\% coarse particles in volume, while in the second event it contains $48 \%$. Moreover, in the 2012 event, the fine mode contains much smaller particles compared with the 2011 event. For example, the central radius of fine mode varies from 0.16 to $0.2 \mu \mathrm{m}$ in 2012 versus 0.23 to $0.26 \mu \mathrm{m}$ in the year 2011 cases, which corresponds to the higher Ångström exponent in 2012 than in 2011 in Fig. 1. In addition, following quite stable behavior of the Ångström exponent in the 2011 and 2012 events in Fig. 1, it is reasonable to derive the average size distribution for the two events. As illustrated in Fig. 7, the 2011 event has a larger fine mode than 2012, but the particle size of fine mode in the 2012 event is smaller. This might be explained by the hygroscopic growth of fine-mode particles; that is, with the increase of water content, fine-particle radius and fine-mode $\mathrm{d} V / \mathrm{d} \ln r$ augment simultaneously.

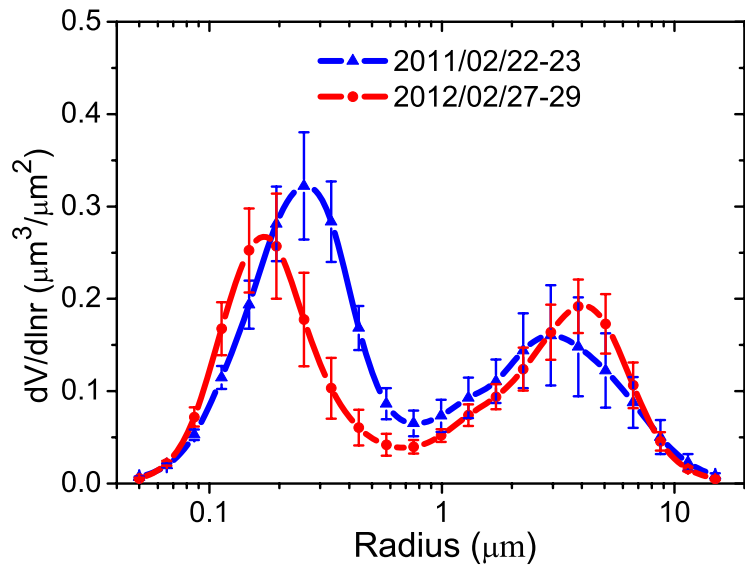

Fig. 7. Comparison of the average size distribution of the two haze events in February 2011 and 2012.

\subsubsection{Refractive indices}

Refractive indices are important physical parameters of aerosol particles and key indicators of aerosol chemical composition. The real part modulates the aerosol scattering coefficient, and indicates information about the water content in aerosols. For example, aerosol mixtures with refractive indices close to 1.33 have an abundance of water content, while those with refractive indices higher than 1.57 are nearly totally dry (Schuster et al., 2009). The imaginary part reflects the aerosol absorbing property, and its spectral pattern can reveal the relative fractions of absorbing aerosols like BC and DU (Schuster et al., 2005; Russell et al., 2010; Wang et al., 2012).

In Fig. 8, we represent the daily average refractive indices during the two haze events in 2011 and 2012. The real parts for all cases exhibit relatively flat behaviors, with the daily average values at four wavelengths concentrated between 1.45 and 1.51. Compared to the real parts, the imaginary parts show obviously spectral variation, with the $440 \mathrm{~nm}$ value significantly higher than that of other bands. The average refractive index during the haze events in 2011 and 2012 

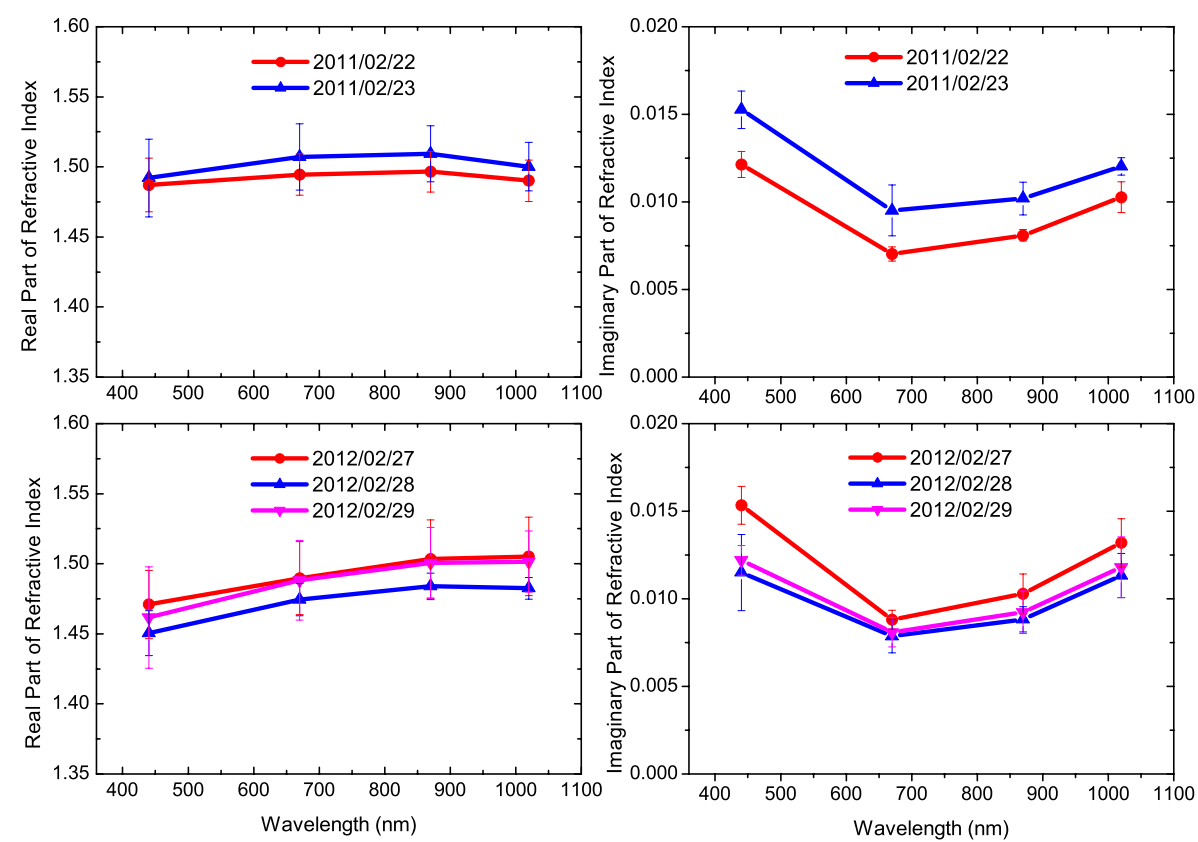

Fig. 8. Daily average aerosol refractive index observed in haze days (top: 2011 event, bottom: 2012 event).

is shown in Fig. 9. The mean value of the real part at $675 \mathrm{~nm}$ is 1.50 in 2011 and 1.48 for 2012. The average imaginary parts at 440 are 0.013 for both of the two events, while they are about 0.008 at $675 \mathrm{~nm}$.

\subsection{Aerosol chemical component fraction during haze events}

Figure 10 shows the volume fractions of the five chemical components of $\mathrm{BC}, \mathrm{BrC}, \mathrm{DU}, \mathrm{AS}$ and $\mathrm{AW}$ for each day during the two haze events. The volume fractions of chemical components exhibit somewhat larger variations (represented by the error bar) within the day, probably caused by the change in the lifetime of different chemical components and the weather conditions (such as temperature, wind velocity and relative humidity). However, the mean volume fraction of each chemical component shows relatively small day-today variations $(<10 \%)$ during each haze event, indicating that the aerosol sources are quite stable throughout each haze event. The average volume fraction of each chemical component for each haze event is presented in Fig. 11. From Fig. 11, one can find that although the haze events occurred in different years, the aerosol chemical composition fractions are comparable to each other, with the difference in volume fraction being less than $5 \%$ absolute. This is partly related to the consistent time period of the two events, i.e., both being in winter.

Among the five components, the $\mathrm{BC}$ and $\mathrm{BrC}$ contents show extremely low levels in all cases with, no more than $2 \%$ and $5 \%$, respectively, in the aerosol. During the two haze events, water occupies a relatively large fraction, rang- ing from 25 to $38 \%$, and 2012 is higher than 2011. From the water fraction, the geometric hygroscopic growth factor $(g H G F)$ of aerosol can be inferred from a simple mathematical formula (Schuster et al., 2009). The $g H G F$ of the 2011 haze event is 1.11 , while it is 1.17 for the 2012 event. When $g H G F$ is larger than 1, the aerosol is hygroscopic (Schuster et al., 2009), indicating that the particle will grow in the presence of water. The DU volume fractions in the two events are around $50 \%$. Even though DU occupies such a large volume fraction in the aerosol during the haze events, it should be noted that this is mainly caused by their large particle size, and the fine-mode fraction $\left(\mathrm{FMF}=\mathrm{AOD}_{\mathrm{f}} / \mathrm{AOD}\right)$ is a more important indicator of the dominant component. The FMF is 0.93 in our case, which means pollution-dominant events with likely a significant amount of the coarse mode composed of fly ash that is related to coal burning (Yang et al., 2009) or dust from local arid-land emissions. Moreover, in situ chemical sampling measurements in Beijing during the wintertime also showed that the dust can account for $50 \%$ of the total aerosol mass concentrations at the surface (Duan et al., 2007; Yuan et al., 2008). The AS accounts for nearly $20 \%$ in the aerosol particles during the haze events. In this study, AS is the proxy for the scattering dry components in the aerosol, which are usually composed of water-soluble and water-insoluble components as well. Hence, it should be noted that AS retrieved in this study is different to that obtained by the chemical sampling approaches, which is normally considered to include only the water-soluble component. 

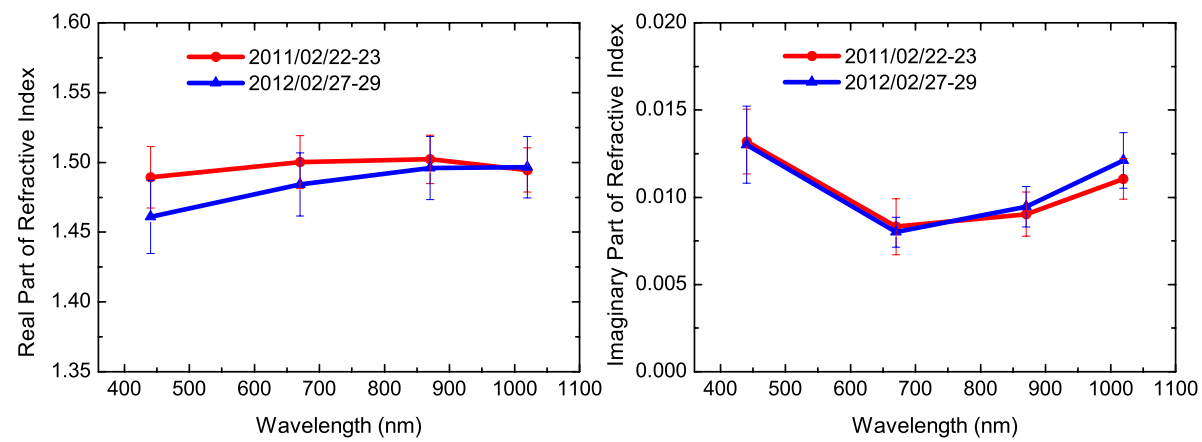

Fig. 9. The average refractive index during the haze events in 2011 and 2012 (left, the real parts; right, the imaginary parts).
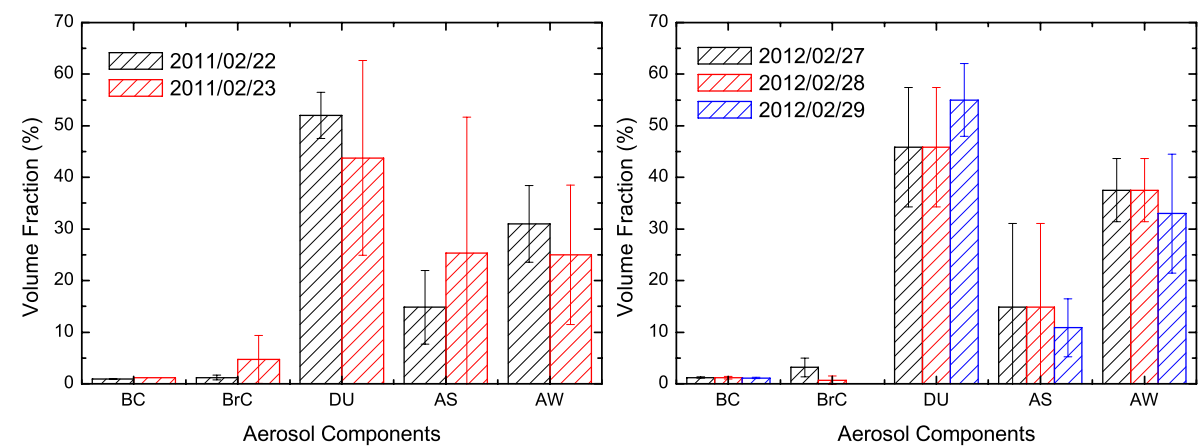

Fig. 10. Daily average percentage of aerosol chemical composition (BC, black carbon; BrC, brown carbon; DU, mineral dust; AS, ammonium sulfate-like component; AW, aerosol water content) retrieved during haze days of 2011 (left) and 2012 (right).

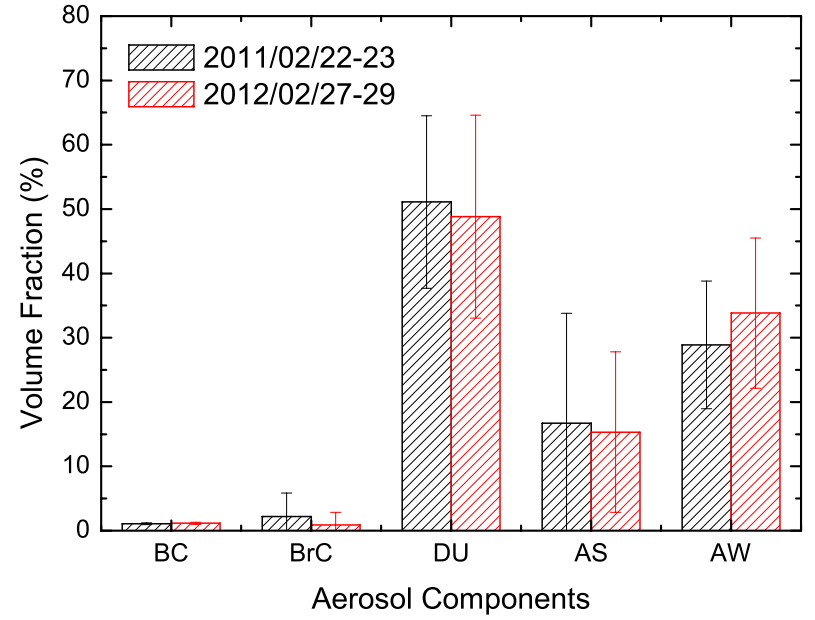

Fig. 11. The average volume fraction of chemical components during the haze events in 2011 and 2012.

\subsection{Average aerosol physical and chemical properties during winter heavy haze event in Beijing}

From Sects. 3.1 to 3.2, we find stable aerosol properties during five days of the heavy haze events in the two years. Therefore, it is reasonable to provide an average example of optical, physical and chemical properties of heavy haze aerosol based on observations during the above two winter haze events in Beijing. As listed in Table 2, during the winter heavy haze events, the aerosols are characterized by large AOD $(440 \mathrm{~nm})$ about $3.01 \pm 0.72$, with an Ångström exponent of about 1.3. The fine-mode AOD is 2.8, corresponding to a fine-mode fraction of 0.93 , suggesting that fine particles dominate the event. The aerosol size distributions are bimodal, and the coarse mode occupies a considerable fraction, which is different from the haze events in cities of southern China such as Guangzhou, where the fine-particle ratio is generally much higher (Tan et al., 2009). The mean particle radius and the standard deviation are $(0.21 \mu \mathrm{m}, 0.51)$ and $(2.9 \mu \mathrm{m}, 0.65)$ for the fine and coarse modes, respectively. With these parameters, the aerosol size distribution over Beijing for haze days can be modeled by a bimodal lognormal function (Dubovik et al., 2002; Schuster et al., 2006):

$$
\begin{aligned}
\frac{\mathrm{d} V(r)}{\mathrm{d} \ln r}= & \frac{C_{\mathrm{f}}}{\sqrt{2 \pi} \sigma_{\mathrm{f}}} \exp \left[-\frac{\left(\ln r-\ln r_{\mathrm{f}}\right)^{2}}{2 \sigma_{\mathrm{f}}^{2}}\right]+\frac{C_{\mathrm{c}}}{\sqrt{2 \pi} \sigma_{\mathrm{c}}} \\
& \exp \left[-\frac{\left(\ln r-\ln r_{\mathrm{c}}\right)^{2}}{2 \sigma_{\mathrm{c}}^{2}}\right],
\end{aligned}
$$

where $r$ is the particle radius, $C_{\mathrm{f}}$ and $C_{\mathrm{c}}$ denote the particle volume concentration for fine and coarse modes, respectively, $r_{\mathrm{f}}$ and $r_{\mathrm{c}}$ are the median radii, and $\sigma_{\mathrm{f}}$ and $\sigma_{\mathrm{c}}$ are the standard deviations as listed in Table 2. 
Table 2. Average heavy haze parameters derived from remote sensing measurements in Beijing winter. (AOD, aerosol optical depth; $\mathrm{AOD}_{\mathrm{f}}$, fine-mode aerosol optical depth; AOD $_{\mathrm{c}}$, coarse-mode aerosol optical depth; $\alpha$, Ångström exponent (440-870 nm); SSA, single-scattering albedo; $r_{\mathrm{f}}$, median radius of fine-mode particles; $\sigma_{\mathrm{f}}$, standard deviation of fine mode; $r_{\mathrm{c}}$, median radius of coarse-mode particles; $\sigma_{\mathrm{c}}$, standard deviation of coarse mode; $C_{\mathrm{f}} / C_{\mathrm{c}}$, ratio of the fine- and coarse-particle volume concentration; $n$, real part of the refractive indices (at 440 and $675 \mathrm{~nm}$, respectively); $k$, imaginary part of the refractive indices (at 440 and $675 \mathrm{~nm}$, respectively); $\mathrm{BC}$, black carbon; BrC, brown carbon; DU, mineral dust; AS, ammonium sulfate-like components; AW, aerosol water).

\begin{tabular}{|c|c|c|c|c|c|c|c|c|c|c|c|c|c|c|}
\hline \multirow{2}{*}{$\begin{array}{l}\text { Para- } \\
\text { meter }\end{array}$} & \multicolumn{5}{|c|}{ Optical properties } & \multicolumn{4}{|c|}{ Physical properties } & \multicolumn{5}{|c|}{ Chemical volume fractions } \\
\hline & $\begin{array}{l}\text { AOD } \\
(440 \mathrm{~nm})\end{array}$ & $\begin{array}{l}\mathrm{AOD}_{\mathrm{f}} \\
(440 \mathrm{~nm})\end{array}$ & $\begin{array}{l}\mathrm{AOD}_{\mathrm{c}} \\
(440 \mathrm{~nm})\end{array}$ & $\alpha$ & $\begin{array}{l}\text { SSA } \\
(440 \mathrm{~nm})\end{array}$ & $\begin{array}{l}\left(r_{\mathrm{f}}(\mu \mathrm{m}), \sigma_{\mathrm{f}}\right) \\
\left(r_{\mathrm{c}}(\mu \mathrm{m}), \sigma_{\mathrm{c}}\right)\end{array}$ & $C_{\mathrm{f}} / C_{\mathrm{c}}$ & $\begin{array}{l}(n 440, \\
k 440)\end{array}$ & $\begin{array}{l}(n 675, \\
k 675)\end{array}$ & $\begin{array}{l}\mathrm{BC} \\
\%\end{array}$ & $\begin{array}{l}\mathrm{BrC} \\
\%\end{array}$ & $\begin{array}{l}\mathrm{DU} \\
\%\end{array}$ & $\begin{array}{l}\mathrm{AS} \\
\%\end{array}$ & $\begin{array}{l}\mathrm{AW} \\
\%\end{array}$ \\
\hline Mean & 3.01 & 2.80 & 0.21 & 1.31 & 0.91 & $\begin{array}{l}(0.21,0.51) \\
(2.90,0.65)\end{array}$ & 1.27 & $\begin{array}{l}(1.48, \\
0.013)\end{array}$ & $\begin{array}{l}(1.49, \\
0.008)\end{array}$ & 1 & 2 & 49 & 15 & 33 \\
\hline SD & 0.72 & 0.72 & 0.04 & 0.12 & 0.01 & $\begin{array}{l}(0.030,0.038) \\
(0.085,0.007)\end{array}$ & 0.38 & $\begin{array}{l}(0.03, \\
0.002)\end{array}$ & $\begin{array}{l}(0.03, \\
0.001)\end{array}$ & 0 & 3 & 11 & 14 & 12 \\
\hline
\end{tabular}

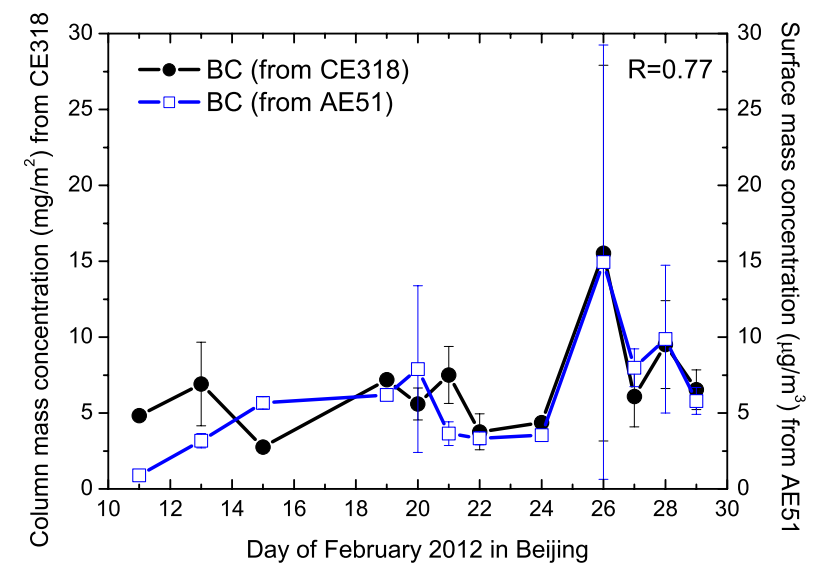

Fig. 12. Daily average $B C$ mass concentration obtained from remote sensing retrievals (CE318) and in situ aethalometer measurements (AE51) during February 2012 in Beijing.

The refractive indices are $1.48-0.013 i$ and $1.49-0.008 i$, respectively, at 440 and $675 \mathrm{~nm}$. The volume fractions of $\mathrm{BC}$, $\mathrm{BrC}, \mathrm{DU}, \mathrm{AS}$ and water contents are 1, 2, 49, 15 and $33 \%$ respectively. If we only consider dry particles, as is considered in the $6 \mathrm{~S}$ radiative transfer model (Vermote et al., 1997) that is widely used in the satellite remote sensing community, and designate $\mathrm{BrC}$ and $\mathrm{AS}$ as the water-soluble components, the volume fractions of $\mathrm{BC}, \mathrm{DU}$, and water-soluble components are 1,73 , and $26 \%$ in the dry particles, respectively, over Beijing. In the $6 \mathrm{~S}$ radiative model, the volume fractions of these three components are 22,70 and $29 \%$ for urban aerosol types and 1,70 and $29 \%$ for continental aerosol types. It can be seen that the aerosol model over Beijing during haze days differs from the standard urban models, but is close to the continental model.

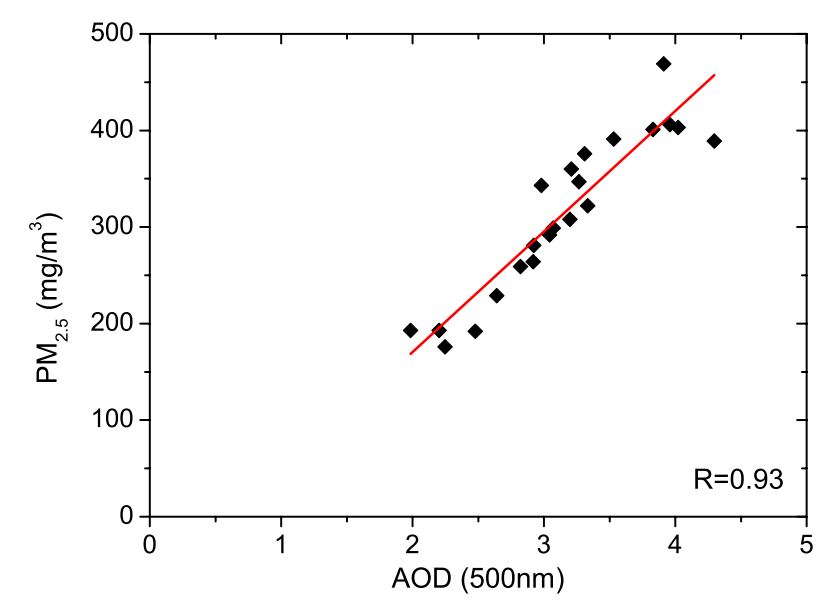

Fig. 13. Comparison of $\mathrm{PM}_{2.5}$ with AOD measurements during the two heavy haze events in Beijing winter.

\section{Discussion}

\subsection{Comparison with in situ BC measurements}

As a preliminary validation, we preformed simultaneous aethalometer (Magee Scientific AE51) measurements in February 2012 at our sun-sky radiometer site. The BC mass concentration obtained from AE51 during this period is plotted in Fig. 12, which corresponds to BC content of the surface layer. Another curve represents the column-integrated $\mathrm{BC}$ mass concentration retrieved from CE318 under the condition of $\operatorname{AOD}(440 \mathrm{~nm})>0.4$. We employed density of BC $\left(2 \mathrm{~g} \mathrm{~cm}^{-3}\right.$ as recommend by Bergstrom, 1972) to convert CE318 retrieved volume value to mass concentration. In the comparison, we selected the AE51 measurements within \pm 15 min of the CE318 retrievals. From Fig. 12, we can see that the trend of the observed and retrieved BC mass is well correlated, with a correlation coefficient of 0.77 . Moreover, the retrieved BC mass can be converted into surface concentration $\left(\mu \mathrm{g} \mathrm{cm}^{-3}\right)$ by assuming a uniform BC column height. 
Conversely, from the good correlation between two curves in Fig. 12, we can estimate that the assumed BC column height is about $1 \mathrm{~km}$ when comparing surface and column $\mathrm{BC}$ concentration. Considering that, in the case of heavy haze, most of aerosols can be constrained somewhat uniformly near the surface (Lv et al., 2013), the planetary boundary layer height (PBLH) can roughly be treated as a proxy of the BC column height. Moreover, the column BC value from CE318 is slightly lower than the surface value on average, which is consistent with the boundary layer height reported by Zhang et al. (1990) from radiosonde measurements, who found that the boundary layer height in Beijing is generally less than $1000 \mathrm{~m}$, usually between 500 and $600 \mathrm{~m}$ in winter.

\subsection{Comparison with in situ $\mathbf{P M}_{2.5}$ measurements}

We compared our observation with in situ hourly $\mathrm{PM}_{2.5}$ measurements located at the US embassy in Beijing (about $10 \mathrm{~km}$ southeast of our site) as shown in Fig. 13. From the comparison we found that the heavy haze events have very high $\mathrm{PM}_{2.5}$ values, ranging from 200 to about $500 \mathrm{mg} \mathrm{m}^{-3}$, while there is quite good correlation between total column AOD and $\mathrm{PM}_{2.5}$. The correlation coefficient of 0.93 is much higher than that of the average condition (Zhang and $\mathrm{Li}, 2013$ ) when we compare AOD with $\mathrm{PM}_{2.5}$ in Beijing. This may be related to a higher fine-mode fraction (here 0.93 ) of haze aerosols. Moreover, it is accepted that aerosol vertical distribution and ambient humidity corrections can also improve the correlation between $\mathrm{AOD}$ and $\mathrm{PM}_{2.5}$ (e.g. Kotchenruther et al., 1999; Tsai et al., 2011). In this regard, the simultaneous observation of AOD from the ground along with $\mathrm{PM}_{2.5}$, aerosol profiles and other environmental factors (e.g. humidity) is very useful to study the AOD-PM 2.5 conversion, which can be used in remote sensing of $\mathrm{PM}_{2.5}$ by satellites from space.

\section{Conclusion}

In this paper, we selected two heavy haze events during winter 2011 and 2012 in Beijing to study optical, physical and chemical characterization of haze aerosols. We proposed a rough selection criterion of $\operatorname{AOD}(440 \mathrm{~nm})>1.0, \alpha>1.0$ and $\mathrm{RH}<90 \%$ to select heavy haze condition, based on the ground-based sun-sky radiometer measurements. We used the state-of-art aerosol retrieval algorithm to derive singlescattering albedo and refractive indices at four wavelengths from 440 to $1020 \mathrm{~nm}$, as well as the particle size distribution of total column aerosols. Then we employed an improved five-component (black carbon, brown carbon, mineral dust, ammonium sulfate-like component and aerosol water content) model to retrieve aerosol chemical composition fractions. The model utilized the spectral refractive indices and single-scattering albedo, and thus can provide more component information than previous three- and four-component models.
Based on the remote sensing observations during haze days in Beijing, a characterization of heavy haze aerosol properties was established, with a large AOD value of about 3.0 at $440 \mathrm{~nm}$ and $\alpha$ of about 1.3. An AOD fine-mode fraction of $93 \%$ proves that small particles dominate these polluted haze events. The aerosol size distribution is bimodal, and the coarse mode occupies a considerable fraction as well. For the refractive indices, the real part exhibits a relatively flat spectral behavior with an average value of about 1.49. The imaginary part shows obviously spectral variation, with the value at $440 \mathrm{~nm}$ (about 0.013 ) larger than the other wavelengths (about 0.008 at $675 \mathrm{~nm}$ ). The chemical composition retrieval shows that black carbon and brown carbon fractions are not larger than 2 and $5 \%$ during the haze. Dust and ammonium sulfate-like components are the main volume contributors of the haze aerosols with volume fractions of $49 \%$ and $15 \%$, respectively, while aerosol water content can reach up to $33 \%$ in volume. These results can be used in various fields; for example, to improve aerosol remote sensing from satellite, characterization of haze in the environmental and climate models, and correction of aerosol blurring effects for Earth observation images from space during the haze condition.

Acknowledgements. This research was supported by the National Natural Science Foundation of China (41222007), the National Basic Research Program of China (973 program) under grant 2010CB950800 (2010CB950801), the CAS Strategic Priority Research Program (XDA05100200) and the European Commission FP-7 project (ACTRIS). The authors thank the three anonymous reviewers for their helpful comments, which helped to improve the paper. We are grateful for the aerosol climatology data of Beijing maintained by Hongbin Chen through AERONET, and the US Embassy of Beijing for providing $\mathrm{PM}_{2.5}$ observation data.

Edited by: D. Tanre

\section{References}

Arola, A., Schuster, G., Myhre, G., Kazadzis, S., Dey, S., and Tripathi, S. N.: Inferring absorbing organic carbon content from AERONET data, Atmos. Chem. Phys., 11, 215-225, doi:10.5194/acp-11-215-2011, 2011.

Bäumer, D., Vogel, B., Versick, S., Rinke, R., Mohler, O., and Schnaiter, M.: Relationship of visibility, aerosol optical thickness and aerosol size distribution in an ageing air mass over South-West Germany, Atmos. Environ., 42, 989-998, doi:10.1016/j.atmosenv.2007.10.017, 2008.

Bergstrom. R. W.: Predictions of spectral absorption and extinction coefficients of an urban air-pollution aerosol model, Atmos. Environ., 6, 247-258, doi:10.1016/0004-6981(72)90083-2, 1972.

Bond, T. C. and Bergstrom, R. W.: Light absorption by carbonaceous particles: An investigative review, Aerosol Sci. Tech., 40, 27-67, 2006.

Deng, X. J., Tie, X. X., Wu, D., Zhou, X. J., Bi, X. Y., Tan, H. B., Li, F., and Hang, C. L.: Long-term trend of visibility and its 
characterizations in the Pearl River Delta (PRD) region, China, Atmos. Environ., 42, 1424-1435, 2008.

Dey, S., Tripathi, S. N. Singh, R. P., and Holben, B. N.: Retrieval of black carbon and specific absorption over Kanpur city, northern India during 2001-2003 using AERONET data, Atmos. Environ., 40, 445-456, 2006.

Duan, F. K., Liu, X. D., He, K. B., Li, Y. W., and Dong, S. P.: Characteristics and source identification of particulate matter in wintertime in Beijing, Water Air Soil Poll., 180, 171-183, doi:10.1007/s11270-006-9261-4, 2007.

Dubovik, O., Smirnov, A., Holben, B. N., King, M. D., Kaufman, Y. J., Eck, T. F., and Slutsker, I.: Accuracy assessments of aerosol optical properties retrieved from Aerosol Robotic Network (AERONET) Sun and sky radiance measurements, J. Geophys. Res-Atmos., 105, 9791-9806, doi:10.1029/2000jd900040, 2000.

Dubovik, O., Holben, B., and Thmoas, F. E.: Variability of absorption and optical properties of key aerosol types observed in worldwide locations, J. Atmos. Sci., 59, 590-608, 2002.

Dubovik, O., Sinyuk, A., Lapyonok, T., Holben, B. N., Mishchenko, M., Yang, P., Eck, T. F., Volten, H., Munoz, O., Veihelmann, B., van der Zande, W. J., Leon, J. F., Sorokin, M., and Slutsker, I.: Application of spheroid models to account for aerosol particle nonsphericity in remote sensing of desert dust, J. Geophys. Res.Atmos., 111, D11208, doi:10.1029/2005jd006619, 2006.

Eck, T. F., Holben, B. N., Sinyuk, A., Pinker, R. T., Goloub, P., Chen, H., Chatenet, B., Li, Z., Singh, R. P., Tripathi, S. N., Reid, J. S., Giles, D. M., Dubovik, O., O’Neill, N. T., Smirnov, A., Wang, P., and Xia X.: Climatological aspects of the optical properties of fine/coarse mode aerosol mixtures, J. Geophys. Res., 115, D19205, doi:10.1029/2010JD014002, 2010.

He, K. B., Huo, H., and Zhang, Q.: Urban air pollution in China: Current status, characteristics, and progress, Annu. Rev. Energ. Env., 27, 397-431, doi:10.1146/annurev.energy.27.122001.083421, 2002.

Holben, B. N., Eck, T. F., Slutsker, I., Tanre, D., Buis, J. P., Setzer, A., Vermote, E., Reagan, J. A., Kaufman, Y. J., Nakajima, T., Lavenu, F., Jankowiak, I., and Smirnov, A.: AERONET - A federated instrument network and data archive for aerosol characterization, Remote Sens. Environ., 66, 1-16, doi:10.1016/S00344257(98)00031-5, 1998.

Holben, B. N., Eck, T. F., Slutsker, I., Smirnov, A. Sinyuk, A., Schafer, J., Giles, D., and Dubovik, O.: Aeronet's Version 2.0 quality assurance criteria, Proc. SPIE, 6408, 64080Q, doi:10.1117/12.706524, 2006.

Kotchenruther, R. A., Hobbs, P. V., and Hegg, D. A.: Humidification factors for atmospheric aerosols off the mid-Atlantic coast of the United States, J. Geophys. Res.-Atmos., 104, 2239-2251, doi:10.1029/98JD01751, 1999.

Lai, L. Y. and Sequeira, R.: Visibility degradation across Hong Kong: its components and their relative contributions, Atmos. Environ., 35, 5861-5872, doi:10.1016/S1352-2310(01)00395-8, 2001.

Li, Z. Q., Goloub, P., Devaux, C., Gu, X. F., Deuze, J. L., Qiao, Y. L., and Zhao, F. S.: Retrieval of aerosol optical and physical properties from ground-based spectral, multi-angular, and polarized sun-photometer measurements, Remote Sens. Environ., 101, 519-533, doi:10.1016/j.rse.2006.01.012, 2006.
Li, Z. Q., Blarel, L., Podvin, T., Goloub, P., Buis, J. P., and Morel, J. P.: Transferring the calibration of direct solar irradiance to diffuse-sky radiance measurements for CIMEL Sun-sky radiometers, Appl. Optics, 47, 1368-1377, doi:10.1364/Ao.47.001368, 2008.

Li, Z. Q., Goloub, P., Dubovik, O., Blarel, L., Zhang, W., Podvin, T., Sinyuk, A., Sorokin, M., Chen, H., Holben, B., Tanré, D., Canini, M., and Buis, J.-P.: Improvements for ground-based remote sensing of atmospheric aerosol properties by additional polarimetric measurements, J. Quant. Spectrosc. Ra., 110, 1954-1961, 2009.

Li, Z. Q., Blarel, L., Podvin, T., Goloub, P., and Chen, L. G.: Calibration of the degree of linear polarization measurement of polarized radiometer using solar light, Appl. Optics, 49, 1249-1256, 2010.

Lv, Y., Li, Z. Q., Xu, H., Li, K. T., Zhang, W. C., and Hou, W. Z.: Joint use of ground-based Lidar and sun-sky radiometer for observation of aerosol vertical distribution, J. Remote Sens., 17, 1008-1020, doi:10.11834/jrs.20133092, 2013.

Menon, S., Hansen, J., Nazarenko, L., and Luo, Y. F.: Climate effects of black carbon aerosols in China and India, Science, 297, 2250-2253, doi:10.1126/science.1075159, 2002.

Moosmuller, H., Chakrabarty, R. K., and Arnott, W. P.: Aerosol light absorption and its measurement: A review, J. Quant. Spectrosc. Ra., 110, 844-878, doi:10.1016/j.jqsrt.2009.02.035, 2009.

Nakajima, T. and Tanaka, M.: Algorithms for radiative intensity calculations in moderately thick atmospheres using a truncation approximation, J. Quant. Spectrosc. Ra., 40, 51-69, 1988.

Nel, A.: Air pollution-related illness: effects of particles, Science, 308, 804-806, 2005.

Okada, K., Ikegami, M., Zaizen, Y., Makino, Y., Jensen, J. B., and Gras, J. L.: The mixture state of individual aerosol particles in the 1997 Indonesian haze episode, J. Aerosol. Sci., 32, 1269-1279, doi:10.1016/S0021-8502(01)00062-3, 2001.

Russell, P. B., Bergstrom, R. W., Shinozuka, Y., Clarke, A. D., DeCarlo, P. F., Jimenez, J. L., Livingston, J. M., Redemann, J., Dubovik, O., and Strawa, A.: Absorption Angstrom Exponent in AERONET and related data as an indicator of aerosol composition, Atmos. Chem. Phys., 10, 1155-1169, doi:10.5194/acp-101155-2010, 2010.

Schuster, G. L., Dubovik, O., Holben, B. N., and Clothiaux, E. E.: Inferring black carbon content and specific absorption from Aerosol Robotic Network (AERONET) aerosol retrievals, J. Geophys. Res.-Atmos., 110, D10s17, doi:10.1029/2004jd004548, 2005.

Schuster, G. L., Dubovik, O., and Holben, B. N.: Angstrom Exponent and bimodal aerosol size distributions, J. Geophys. Res. Atmos., 111, D07207, doi:10.1029/2005JD006328, 2006.

Schuster, G. L., Lin, B., and Dubovik, O.: Remote sensing of aerosol water uptake, Geophys. Res. Lett., 36, L03814, doi:10.1029/2008g1036576, 2009.

Sinyuk, A., Holben, B. N., Smirnov, A., Eck, T. F., Slutsker, I., Schafer, J. S., Giles, D. M., and Sorokin, M.: Assessment of error in aerosol optical depth measured by AERONET due to aerosol forward scattering, Geophys. Res. Lett., 39, L23806, doi:10.1029/2012GL053894, 2012.

Smirnov, A., Holben, B. N., Eck, T. F., Dubovik, O., and Slutsker, I.: Cloud-screening and quality control algorithms for the AERONET database, Remote Sens. Environ., 73, 337-349, doi:10.1016/S0034-4257(00)00109-7, 2000. 
Stamnes, K., Tsay, S. C., Wiscombe, W., and Jayaweera, K.: Numerically stable algorithm for discrete-ordinate-method in multiple-scattering and emitting layered media, Appl. Optics, 27, 2502-2509, 1988.

Sun, Y. L., Zhuang, G. S., Tang, A. H., Wang, Y., and An, Z. S.: Chemical characteristics of $\mathrm{PM}_{2.5}$ and $\mathrm{PM}_{10}$ in haze-fog episodes in Beijing, Environ. Sci. Technol., 40, 3148-3155, doi:10.1021/Es051533g, 2006.

Tan, J. H., Duan, J. C., Chen, D. H., Wang, X. H., Guo, S. J., Bi, X. H., Sheng, G. Y., He, K. B., and Fu, J. M.: Chemical characteristics of haze during summer and winter in Guangzhou, Atmos. Res., 94, 238-245, doi:10.1016/j.atmosres.2009.05.016, 2009.

Tsai, T. C., Jeng, Y. J., Chu, D. A., Chen, J. P., and Chang, S. C.: Analysis of the relationship between MODIS aerosol optical depth and particulate matter from 2006 to 2008, Atmos. Environ., 27, 4777-4788, 2011.

Vermote, E., Tanré, D., Deuzé, J. L., Herman, M., and Morcrette, J. J.: Second simulation of the satellite signal in the solar spectrum, 6S: an overview, IEEE T. Geosci. Remote, 35, 675-686, 1997.

Volten, H., Munoz, O., Rol, E., de Haan, J. F., Vassen, W., Hovenier, J. W., Muinonen, K., and Nousiainen, T.: Scattering matrices of mineral aerosol particles at $441.6 \mathrm{~nm}$ and $632.8 \mathrm{~nm}$, J. Geophys. Res., 106, 17375-17401, 2001.

Wang, L., Li, Z. Q., Li, D. H., Li, K. T., Tian, Q. J., Li, L., Zhang, Y., Lu, Y., and Gu, X. F.: Retrieval of Dust Fraction of Atmospheric Aerosols Based on Spectra Characteristics of Refractive Indices Obtained from Remote Sensing Measurements, Spectrosc. Spect. Anal., 32, 1644-1649, doi:10.3964/j.issn.10000593(2012)06-1644-06, 2012.
Wang, L., Li, Z. Q., Tian, Q. J., Ma, Y., Zhang, F. X., Zhang, Y., Li, D. H., Li, K. T., and Li, L.: Estimate of aerosol absorbing components of black carbon, brown carbon, and dust from groundbased remote sensing data of sun-sky radiometers, J. Geophys. Res.-Atmos., 118, 6534-6543, doi:10.1002/jgrd.50356, 2013.

Wu, D., Tie, X. X., Li, C. C., Ying, Z. M., Lau, A. K. H., Huang, J., Deng, X. J., and Bi, X. Y.: An extremely low visibility event over the Guangzhou region: A case study, Atmos. Environ., 39, 6568-6577, doi:10.1016/j.atmosenv.2005.07.061, 2005.

Yang, M., Howell, S. G., Zhuang, J., and Huebert, B. J.: Attribution of aerosol light absorption to black carbon, brown carbon, and dust in China - interpretations of atmospheric measurements during EAST-AIRE, Atmos. Chem. Phys., 9, 2035-2050, doi:10.5194/acp-9-2035-2009, 2009.

Yuan, H., Zhuang, G. S., Li, J., Wang, Z. F., and Li, J.: Mixing of mineral with pollution aerosols in dust season in Beijing: Revealed by source apportionment study, Atmos. Environ., 42, 2141-2157, doi:10.1016/j.atmosenv.2007.11.048, 2008.

Zhang, A. C., Sun, C. G., and Tian, Y.: Observing results of atmospheric mixed layer in Beijing district and the assessment of theoretical models, Acta Meteorologica Sinica, 48, 345-354, 1990.

Zhang, Y. and Li, Z. Q.: Estimation of $\mathrm{PM}_{2.5}$ from finemode aerosol optical depth, J. Remote Sens., 17, 929-943, doi:10.11834/jrs.20133063, 2013.

Zhao, F., Tan, Y., Li, Z., and Gai, C.: The effect and correction of aerosol forward scattering on retrieval of aerosol optical depth from Sun photometer measurements, Geophys. Res. Lett., 39, L14805, doi:10.1029/2012GL052135, 2012. 